This is an electronic reprint of the original article. This reprint may differ from the original in pagination and typographic detail.

Author(s): Paloviita, Ari; Puupponen, Antti; Kortetmäki, Teea; Silvasti, Tiina

Title: $\quad$ Measuring Vulnerability in the Food System

Year: $\quad 2015$

Version:

Please cite the original version:

Paloviita, A., Puupponen, A., Kortetmäki, T., \& Silvasti, T. (2015). Measuring

Vulnerability in the Food System. Food Studies : An Interdisciplinary Journal, 5(3), 59-

70. https://doi.org/10.18848/2160-1933/cgp/v05i03/40507

All material supplied via JYX is protected by copyright and other intellectual property rights, and duplication or sale of all or part of any of the repository collections is not permitted, except that material may be duplicated by you for your research use or educational purposes in electronic or print form. You must obtain permission for any other use. Electronic or print copies may not be offered, whether for sale or otherwise to anyone who is not an authorised user. 


\title{
Measuring Vulnerability in the Food System
}

\author{
Ari Paloviita, Antti Puupponen, Teea Kortetmäki, and Tiina Silvasti, \\ Department of Social Sciences and Philosophy, University of Jyväskylä, Finland
}

\begin{abstract}
Food system vulnerability is an emerging concept for food security policies and food supply chain management. Hence, measuring food system vulnerability is necessary for developing appropriate food security policies and managing food supply chain vulnerabilities. In this paper, we aim to clarify the development process of food system vulnerability indicators. We conducted an abducted qualitative content analysis based on public documents of various Finnish organizations, including ministries and administration, interest organizations, NGOs, food sector enterprises, and a church. We analysed the engagement level of various organizations in food security and identified vulnerability aspects in the Finnish food system. This was followed by the evaluation of relevant goals, potential target groups, and functions, as well as of the temporal and spatial boundaries of food system vulnerability indicators. We found that most of the Finnish organizations do not explicitly address national food security, which implies that food security is considered self-evident. However, various social, economic, environmental, and institutional vulnerabilities were identified. We conclude that, even in a basically food-secure country such as Finland, measuring external and internal factors of vulnerability should be seriously addressed. Moreover, fundamental elements of sustainability should be built-in characteristics of any set of vulnerability indicators. Food system vulnerability indicators enable identification and communication of vulnerability both at national, regional, and food supply chain levels.
\end{abstract}

Keywords: Food system, vulnerability indicators, food security, food supply chain management

\section{Introduction}

$\mathrm{F}$ ood system vulnerability is an emerging concept for food security policies and food supply chain management. As food systems - that is, webs of food producers, distributors, processors, manufacturers, retailers, and consumers - have become more globalized and more complex, they have faced new types of social, environmental, economic, and institutional vulnerabilities. Failure to provide food security has been recognized as one of the most critical (undesirable) indicator outcomes of food system vulnerability (Eakin 2010, 81). Food safety, which is an integral part of food security, has been threatened by a number of events, such as the outbreak of Foot and Mouth Disease in the UK in 2001, the occurrence of Hurricane Katrina in New Orleans in 2005, and the European horsemeat scandal in 2013. The vulnerability of contemporary food systems and food supply chains has been demonstrated also by climate change, exhaustion of many natural resources, and insecurity of the supply of agricultural raw materials and water. As a result, concepts somehow neglected in the past, such as resilience and vulnerability, have emerged at the forefront of food system research in the last ten years (see, for example, Ponis and Koronis 2012). Still, food system vulnerability is a relatively unexplored area in food supply chain management/food system research. Measuring food system vulnerability is necessary for developing appropriate food security policies and managing food supply chain vulnerabilities. Hence, vulnerability indicators have been introduced to provide information for decision makers (Birkmann 2013).

The Finnish food system, which is in the focus of this paper, is a modern European food system with high ethical, environmental, and social standards. Increasing international competition, globalized food supply networks, increasing food imports, a decreasing number of farms, and the centralization and consolidation of the food and retail industries characterize the Finnish food system. In the Finnish context, food security is an important issue for several reasons. First, the share of food imports has substantially increased the past couple of decades. Currently, the share of food imports in the value of national food use is approximately 25\% (Knuuttila and Vatanen 2013, 47). Second, domestic food production is increasingly dependent on imports due to insufficient domestic energy, chemicals, fodder protein, and other input production (Knuuttila and Vatanen 2013, 46-47). Third, the increase of food prices in Finland between 2008 and 2013 was the second highest among countries in the European Union (Statistics Finland 2013). Food prices increased more rapidly only in the United Kingdom. Fourth, there are large families, low-income pensioners, unemployed people, students, and immigrants who receive food aid in Finland, especially in Eastern and Northern Finland, where access to food has become difficult due to closure of village shops and longer distances to fetch groceries (Evangelical Lutheran Church of Finland 2013). Against this background, it is fair to claim that there are elements in the Finnish food system that increase both current and future food insecurity in Finland.

In this paper, we aim to clarify the development process of vulnerability indicators in the context of the Finnish food system. We conducted an abductive qualitative content analysis based on public documents of various Finnish organizations including ministries and administration, interest organizations, NGOs, food sector enterprises, and a church. This study will address the following research questions: (1) How well are various Finnish organizations engaged in food security at the national level? (2) What types of food system vulnerabilities can be identified in public documents? (3) What purposes could be served by measuring food system vulnerability? (4) What target groups and functions could be served by measuring food system vulnerability? (5) What spatial and temporal boundaries should be used in measuring food system vulnerability?

The paper is structured in the following way. A theoretical overview includes discussion on food systems and food security, as well as on vulnerability indicators. A literature review is followed by a description of the method and the 
data. Then, we present the results in order to answer the research questions. We conclude by discussing managerial and policy implications of the research.

\section{Food System Vulnerability}

A food system is a complex system that includes food businesses, the natural environment, and society as a whole. Hence, there are economic, environmental, social, and institutional dimensions of food system vulnerability. Food businesses operate food supply chains, which include input supply industries, primary production, food processing and manufacturing, food retailing, food services, and food consumption. Concepts such as supply chain vulnerability and supply chain resilience have emerged to increase the understanding of the vulnerabilities of the food supply chain (Peck 2005; Ponis and Koronis 2012). Also, the economic vulnerability of other economic systems and different occupations or livelihoods to various risks can be studied (Birkmann 2013, 28). For example, states, private companies, or households are vulnerable in terms of economic losses due to external stressors. On the other hand, concepts such as ecosystem vulnerability or environmental vulnerability focus on ecological function and ecosystem services and the degradation of environmental services and functions (Birkmann 2013, 29; Ericksen et al. 2010, 69). For example, landuse and land-cover change due to converting natural ecosystems into agricultural production may have negative impacts on biodiversity, habitat integrity, soil structure, and nutrient cycles (Ericksen et al. 2010, 69). The social dimension of vulnerability, in turn, focuses on human welfare and livelihood strategies with aspects of justice, social differentiation, and societal organization (Adger and Kelly 1999). For example, poverty, social marginalization and powerlessness, demography, social networks, education, health, and well-being are all social vulnerability issues (Birkmann 2013, 26). Moreover, modes and constraints in governance, underlying rules and norm systems, political economy, and the capacity of organizations to deal with risks can be framed as an institutional dimension of vulnerability (Birkmann 2013, 30-31). For example, potential mismatches between governmental (formal institution) and non-governmental (informal institution) food security strategies refer to institutional vulnerability.

\section{Food System and Food Security}

A food system is a relatively recent approach in order to conceptualize and operationalize complex interactions and interdependencies among food production, food processing and manufacturing, food retailing, and food consumption. A system-based approach is necessary, especially in the assessment of the interactions between economic, environmental, social, and political issues. Ericksen et al. (2010, 30) note that researchers must acknowledge that food systems serve different functions for different stakeholders with different valuation criteria, which means that trade-offs are inevitable. For example, from a food business - that is, food industry and food retailing - point of view, food system activities are typically viewed as value-adding food supply chain systems. Hence, food supply chain management addresses issues related to supplier relationships, information management, logistics, and consumer satisfaction. However, managing broader societal issues, such as food security and sustainability, requires system approaches that go beyond conventional food supply chains. It means recognizing changing environmental, economic, and social conditions and their linkages to food system activities.

Food security and sustainability are important outcomes of a food system (Ericksen et al. 2010, 25). Vulnerable food systems, in turn, may fail to provide food security or to manage a food system sustainability (Eakin 2010, 81). Food system activities face vulnerability due to multiple stresses and changes, which means that the capacity of food system activities and actors to deliver positive results in terms of food security and sustainability is vulnerable. Food security involves four dimensions: (1) adequacy of food supply or availability, (2) accessibility to food or affordability, (3) utilization or quality and safety of food, and (4) stability of supply without seasonal fluctuations or shortages (UNEP 2009, 78). According to Brunori and Guarino (2010, 41), food security has recently become a familiar phrase in the European mass media also due to environmental, oil, food, and financial crises. Hence, food security is a social issue, which is strongly linked to economic and environmental issues as well. Climate change, peaks in oil prices, fuel/food competition, nutritional transition in emerging countries, and financial speculation on food commodities are drivers of food security consideration both in the North and in the South of Europe (Brunori and Guarino 2010, 45). In the UK, the Economic and Social Research Council and the Food Standards Agency have recently funded research projects related to food system resilience, safety and security, food price volatility, and food supply chain management (ESRC 2014). At the EU level, research project Transmango focuses on the vulnerability and resilience of European food systems in a context of socio-economic, behavioural, technological, institutional, and agro-ecological change with vulnerability assessment methodologies (Transmango 2014). Obviously, the ability to measure the vulnerability of a food system is an essential prerequisite for reducing food security risk and for adaptation strategies.

\section{Vulnerability Indicators}


Barsley et al. (2013, 9) divide vulnerability methodologies into indicator-based methodologies, model- and GIS-based (geographical information system) methodologies, and stakeholder-based methodologies. Vulnerability indicators are the offspring of economic indicators (such as GDP), social indicators, environmental indicators, and sustainability indicators. Birkmann $(2013,87)$ defines a vulnerability indicator as a variable which is "an operational presentation of a characteristic or quality of an object or subject able to provide information regarding the susceptibility, coping and adaptive capacity and resilience of a system to an impact." Susceptibility is sometimes called sensitivity or fragility, which refers primarily to the conditions of the community or system exposed (Birkmann 2013, 25). Various capacities related to coping and adaptation are closely linked to the concept of resilience, which describes the capacities of societies, communities, individuals, or social-ecological systems to deal with adverse consequences and impacts (Holling 2003). There are several applications of environmental vulnerability indicators (Villa and McLeod 2002), social vulnerability indicators (Lee 2014), and economic vulnerability indicators (Smith and Subandoro 2007, 94). Vulnerability indicators are typically used to monitor trends on regional and national scales (Schröter et al. 2005). Hence, vulnerability indicators are closely related to vulnerability assessments, vulnerability analysis, and vulnerability mapping. According to Schröter et al. (2005), limitations of vulnerability indicators include (1) lack of universally applicable metric for vulnerability, (2) difficulties finding quantitative indicators for adaptive capacity that can capture qualitative findings, (3) data availability, and (4) aggregation of information.

Vulnerability indicators measuring modern food system vulnerability or food security vulnerability are rare. Typically, food system vulnerabilities are measured in a developing country context or they are restricted to agricultural production or vulnerable ecosystems. In addition, contemporary vulnerability indicators are heavily biased to climate change vulnerabilities. According to Benson et al. $(2008,18)$, changes in food security vulnerability indicators may be used in monitoring to diagnose a serious problem occurring for some population in some location. For example, household/regional/national resilience to food insecurity can be measured. In the United States, the food and agriculture sector was identified as one of the critical infrastructures following the attacks of September 11, 2001, which motivated a report on the vulnerability assessments of food systems (FDA 2012).

\section{Materials and Method}

We conducted an abductive, qualitative content analysis based on public documents of the various Finnish organizations listed in table 1 . The organizations were selected based on their potential relevance and interest in food system development and food security. Moreover, these organizations were supposed to represent the key public and private stakeholders in the Finnish food system and food supply chains. First, all ministries (eight) dealing with foodrelated issues were selected. In addition, some of the key agencies and institutes in the administrative sector of the ministries were selected, such as Agrifood Research Centre Finland (Ministry of Agriculture and Forestry), the National Emergency Supply Agency (Ministry of Employment and the Economy), and the Finnish Environment Institute (Ministry of the Environment). It should be noted that there is no dedicated ministry of food in Finland. Second, the largest food manufacturers and retailers in Finland were selected. This set of organizations included nine food manufacturing companies and four retailing companies. Third, four interest organizations were selected, representing different food system activities: agriculture, food industry, trade, and consumption. Fourth, six non-governmental organizations were selected based on their contribution to the discussion on food security or sustainable food systems. Finally, the biggest food aid distributor in Finland, the Evangelical Lutheran Church of Finland, was selected. The data consisted of various documents publicly available on the Internet. The documents were annual reports, responsibility reports, strategies, facts, policies, policy positions, project descriptions, studies, cases, official statistics, and news available on the webpages of the selected organizations.

Table 1: Finnish organizations selected for the search of public documents

\begin{tabular}{|l|l|}
\hline Ministries and administration & $\begin{array}{l}\text { Food processors, manufacturers, wholesalers, and } \\
\text { retailers } \\
\text { Ministry of Agriculture and Forestry }\end{array}$ \\
$\begin{array}{l}\text { Agrifood Research Finland MTT } \\
\text { Finnish Food Safety Authority EVIRA }\end{array}$ & $\begin{array}{l}\text { The Central Union of Agricultural Producers and Forest } \\
\text { Owners }\end{array}$ \\
Ministry of Employment and the Economy & Finnish Food and Drink Industries' Federation \\
National Emergency Supply Agency & Finnish Commerce Federation \\
$\begin{array}{l}\text { Centres for Economic Development, Transport and the } \\
\text { Environment }\end{array}$ & Finnish Competition and Consumer Authority \\
\hline
\end{tabular}




\begin{tabular}{|l|l|}
\hline National Consumer Research Centre & Non-governmental Organizations \\
Finnistry of the Environment & The Finnish National Rescue Association \\
Ministry of Social Affairs and Health & The Finnish National Organization of the Unemployed \\
Ministry of Finance & The Mannerheim League for Child Welfare \\
Ministry of Defence & The Finnish Red Cross \\
Ministry of the Interior & The Finnish Organic Association \\
Ministry of Transport and Communications & Finfood Association \\
& Evangelical Lutheran Church of Finland \\
\hline
\end{tabular}

The abductive content analysis connects the coding schemes of data-based and theory-directed analysis (Hsieh and Shannon 2005). Hence, the abductive coding scheme recognizes both the codes derived from earlier research or theory formation as well as purely data-based codes. The approach helps in abandoning old convictions and in finding novel insights. According to Reichertz (2010), "it is an attitude towards data and towards one’s own knowledge: data are to be taken seriously, and the validity of previously developed knowledge is to be queried.” Abductive reasoning aims to uncover hidden regularities by identifying surprising facts, like new or earlier unidentified food system vulnerabilities. Consequently, it offers a practical tool for the development of vulnerability indicators in the context of the Finnish food system. Large amounts of collected data were systematically analysed by looking at the data from the perspective of the five research questions, focusing on (1) engagement in food security, (2) food system vulnerabilities, (3) the goals of food system vulnerability indicators, (4) target groups and function of vulnerability indicators, and (5) the temporal and spatial boundaries of vulnerability indicators. All the selected excerpts (block quotations) from the data are originally published in English—-that is, they are not translations.

\section{Results}

\section{Engagement in Food Security}

It was discovered that food security is mainly discussed in the context of Finland's Development Policy Program-that is, from the perspective of food security vulnerability in developing countries. Food security in Finland was briefly mentioned by some ministries and other organizations. The approaches were related to mainly the emergency supply of food or climate change adaptation. Food supply chain actors were concerned about mainly food self-sufficiency and food safety, which are part of overall food security. Non-governmental organizations and the church were more focused on food insecure individuals and households.

We found out that the concept "food security" was rarely used in the public documents in the context of the Finnish food system. Finnish food system is a modern food system with efficient and standardized food supply chains, and it is commonly documented to be relatively resilient to external risks and to have high adaptive capacity. The consequence of this rather self-confident view is that there is a lack of critical discussion on overall food security at the national, regional, and food supply chain levels. In addition, a holistic perspective regarding food security and food system vulnerability seems to be missing. However, separate dimensions of food security, such as adequacy of food supply, food safety, food affordability, and the stability of food supply, were addressed by different ministries or organizations. Hence, discussion on food security was fragmented or focused on narrow issues. Moreover, food security seems to be firmly sectorized, with individual ministries encompassing either social, environmental, or economic dimensions of food security. This problem is clearly addressed in the National Strategic Research Agenda for Food Research by ETP Food for Life Finland (the report link was found on the webpage of Finnish Food and Drink Industries’ Federation):

Cooperation between all parties in the chain and the open transfer of information are the cornerstones of strategy-based operations. To support this, the strategy proposes the establishment of a food policy programme for matters that fall within the scope of different ministries in order to clarify and simplify the dispersed 
administration and management of food chain-related matters, and additionally, the establishment of a "Food policy working group” to monitor strategy implementation. (ETP Food for Life Finland 2011)

Addressing a multidimensional issue such as food security requires a holistic food policy approach or a food supply chain management approach. In the current situation it is rather difficult to manage food security with only a single ministry or a single organization. We argue that the lack of commitment to food security in Finland is mainly due to lack of appropriate administration and management.

\section{Food System Vulnerabilities}

Environmental, social, economic, and institutional vulnerabilities in the Finnish food system were identified based on the abductive content analysis. The social dimension included issues related to labour, health (food safety), social inequality, and poverty. The economic dimension was addressed by issues such as profitability and the competitiveness of food supply chains, food prices, energy supplies, and food system infrastructures (logistics). Climate change mitigation and adaptation, food waste, and the use of non-renewable energy sources were the most commonly addressed issues with regard to the environmental dimension of vulnerability. Finally, the institutional dimension of vulnerability was illustrated by the public documents discussing political decision-making processes (WTO/the EU) at different levels: national and regional food policies and embargos and sanctions on food imports, especially between the EU and Russia.

Food system vulnerabilities were not directly associated with food security in the public documents, but quite commonly, they were linked to sustainability frameworks. Moreover, vulnerabilities in the Finnish food system were typically seen as external factors caused by international and global changes, as was highlighted in the Government Report on Finnish Security and Defence Policy by the Parliament of Finland/ Foreign Affairs Committee:

Food security is increasingly dependent on international factors. Finland's dependence on foreign exports for its food security is 25 per cent. However, information received by the Committee indicates that the level of food security in Finland is high. This is based on a high degree of self-sufficiency in primary production in key product groups, domestic processing capacity and the good functioning capability of key sectors. Information received by the Committee indicates that maintaining this level of preparedness calls for preserving the profitability and competitiveness of the food sector.

Hence, the documents tend to suggest that the Finnish food system is resilient to external risks with a high degree of adaptive capacity. However, emerging economic vulnerabilities related to global food markets and environmental vulnerabilities related to global environmental change are recognized by many organizations.

\section{Goals of Food System Vulnerability Indicators}

Definition or selection of relevant goals is the first phase of vulnerability indicator development (Birkmann 2013, 93). Goals of vulnerability indicators or vulnerability measurement were not explicitly mentioned or formulated in our data. Hence, it is not possible to identify a direct link between the data and the goals of food system vulnerability indicators. However, certain visions related to food security or food system vulnerability can be identified in the public documents. The first guiding vision for food system vulnerability indicators might be the shift in focus from separate activities of the food system to the food system overall. Hence the set of vulnerability indicators should represent all interlinked activities of the food system: input production, agriculture, food processing and manufacturing, delivery, and consumption. In the national food security report by the MTT Agrifood Research Centre, for example, it is recognized that a broader food system approach is needed:

Maintaining food security involves much more than just agriculture. A matter of particular importance is to have the logistical system and infrastructure supporting Finland's food supply chain on a sustainable level. The logistical system based on the so-called lean philosophy, or small stockpiles and re-stocking at the last possible moment, on which the Finnish food sector operates is vulnerable to disruptions caused by, for example, extreme weather conditions, IT system failures, interruptions to fuel and other energy supplies or problems in delivery systems.

On the other hand, according to our data, there have been attempts to measure food system sustainability in Finland. Hence, the second guiding vision for food system vulnerability indicators might be to link vulnerability indicators to sustainability goals. Addressing sustainability goals in vulnerability indicator development could be a step towards sustainable and secure food systems (Lang and Barling 2012). This would also be conceptually logical as the thematic dimensions - economic, environmental and social-are the same in both concepts. The general vision of combining vulnerability reduction and sustainability improvements simultaneously should be complemented with more precise goals derived from the participative stakeholder involvement process. 


\section{Target Groups and Functions}

Identifying the target groups and the associated functions for which the vulnerability indicators will be used is the second step in vulnerability indicator development (Birkmann 2013, 93). Potential target groups for food system vulnerability indicators are policy makers, regional authorities, and food supply chain actors. These target groups can use vulnerability indicators for identification and communication of vulnerability at national, regional, and food supply chain levels. At the national level, key functions of vulnerability indicators can include policy recommendations and best practices to decrease vulnerability. Regional authorities, in turn, can use vulnerability indicators in comparing different regions and in developing regional food systems. At the food supply chain level, food retailers and wholesalers, as well as food processors and manufacturers, can assess supply chain vulnerability as part of overall food supply chain management and risk management, as illustrated in the corporate responsibility report by a Finnish food retailer Kesko:

With respect to products offered to customers, the aim is to assess the impact of their entire life cycles on consumption. The transparency and responsibility of purchasing chains have become increasingly important. Increasingly detailed information on the origin and manufacturing methods of products needs to be made available to customers. Care must be taken that responsibility is realised in all operations and throughout the supply chain. Diversified networking with suppliers of goods and providers of services requires that all supply chain operators adopt the same values, objectives and operating practices. A failure in product safety control or in the quality assurance of the supply chain can result in financial losses, the loss of customer confidence or, in the worst case, a health hazard to customers.

The food industry and retail companies rarely explicitly address vulnerabilities in the food supply chain or food security. However, they usually aim to identify supply chain risks associated with suppliers. Risk of financial or reputational losses is typically the key driver for collecting and analysing supply chain data.

\section{Temporal and Spatial Boundaries}

Identifying the timeframe over which vulnerability indicators are to be measured and determining the spatial bounds of the reporting unit constitute another important step in vulnerability indicator development (Birkmann 2013, 93). The appropriate timeframe for current vulnerability indicators describing recent development trends based on historic data is typically ten to twenty years. Projections generating future vulnerability indicators may cover twenty to forty years. Many changes, such as climate change, are slow processes, which require a sufficient timeframe to show the gradual change in the system. In the case of the Finnish food system, the national boundary offers a meaningful spatial scope for vulnerability indicators. Finland is bordered by Sweden to the west, Norway to the north, Russia to the east, and the Baltic Sea to the south. The Finnish food system is a rather isolated system geographically as there is very little collaborative interaction between Russian, Swedish, and Finnish food systems. However, Russia (28.9\% of the value of exports) and Sweden (18.5\%) are the most important export countries for Finnish food products (Finnish Food and Drink Industries' Federation 2013). Sweden (11.6\% of the value of imports) is also the second largest import country of food products after Germany (ibid.). Alternatively, spatial boundaries of vulnerability indicators can be based on regional boundaries or specific foodsheds - that is, the geographic areas that feed population centres (Peters et al. 2009). In some product groups, however, organizational boundaries may be useful. For example, the Finnish dairy system is essentially managed by two large industrial operators. According to National Consumer Research Centre, Finnish dairyproduct manufacturer Valio purchases $86 \%$ of the milk produced in Finland. Hence, vulnerability of one single organization can increase the vulnerability of the whole national food system, as was illustrated by the introduction of Russian embargo on the EU food products in 2014. The following excerpt was taken from Valio's web page:

Valio's share of Finnish food exports subject to Russian embargo over 85\%. Valio will be hit by far the hardest of all companies in Finland by Russia's import restrictions. ... The manufacture of all Valio products destined for Russian export was halted on Thursday, 7th August 2014, while that of products for the Finnish and other markets continues as normal. Negotiations in accordance with the Finnish Act on Co-operation within Undertakings are to commence on the adaptation of the number of employees to the decreasing production volumes. ... Valio is obligated to process all the raw milk produced by its owners, the Valio milk producers. Alternative markets for the milk are being sought.

In Valio's case, the impacts of the embargo were realised in all parts of the Finnish dairy system. First, farmers were hit by lower producer prices because the main export market disappeared. Second, more than one hundred dairy industry employees were fired because Valio had to decrease production capacity in Finland. Third, national dairy retail markets were shaken by the surplus volumes of Valio's cut-price "Putin cheese.” Valio's competitors accused Valio of dumping its cheaper cheese on domestic markets. Fourth, Valio temporarily made cheese affordable to more consumers. 
All these elements introduced a threat for long-term profitability of domestic dairy production, processing, and manufacturing.

\section{Discussion and Conclusion}

In this section, each research question is discussed based on the empirical findings. In addition, findings are contextualized in a wider context of vulnerability measurements, and the practical suggestions for policy making and further research are made. The limitations of the study are also discussed.

(1) How well are various Finnish organizations engaged in food security at the national level? Although food security as a concept was rarely used in our data, various organizations addressed explicitly individual dimensions of food security - that is, the adequacy of food supply or availability, accessibility to food or affordability, utilization of or quality and safety of food, and the stability of food supply. The low level of engagement or commitment to food security can be the result of the lack of coherent food policy in Finland or the lack of food security measurements.

(2) What types of food system vulnerabilities can be identified in public documents? Our data suggest that food security in Finland is not self-evident, due to various environmental, economic, social, and institutional vulnerabilities in the Finnish food system. Ministry of the Environment, its administration, and some NGOs highlight environmental vulnerabilities of the food system related to climate change, waste, and agricultural emissions. Interest groups such as The Central Union of Agricultural Producers and Forest Owners and Finnish Food and Drink Industries’ Federation, as well as many food manufacturing companies, address economic vulnerabilities related to weak profitability. The Evangelical Lutheran Church of Finland and some NGOs point out social vulnerabilities related to food aid and equality. Institutional vulnerabilities, such as centralized food system activities or dispersed administration and management of food chain-related matters were identified in more research-oriented reports.

(3) What purposes could be served by measuring food system vulnerability? No specific goals for vulnerability indicators were explicitly mentioned or formulated in our data. However, we identified two broader visions, which could serve as a starting point for vulnerability indicator development. First, there is a vision for moving towards holistic measurement of food system vulnerability, including all activities of the food system, all dimensions of food security, and all dimensions of sustainable development. This type of approach requires identifying critical linkages in the function of food system, distribution mechanisms of food, and consequences to sustainability (Eakin 2010, 83). Effective reduction of vulnerability is not possible without coordination and management across scales and political boundaries. Second, vision relates to the first one, suggesting that vulnerability indicators could be linked to sustainability goals. Hence, reducing vulnerability and improving sustainability of the food system could be assessed, coordinated, and managed within a common framework.

(4) What target groups and functions could be served by measuring food system vulnerability? The key additional questions here are: What activities are vulnerable, and who is vulnerable? According to our data, it seems that the most vulnerable activities in the Finnish food system are agriculture, food manufacturing, and consumption. In agriculture, farmers are facing economic, environmental, social, and institutional pressures. The food industry, which mainly consists of small- and medium-sized enterprises, is similarly vulnerable to multiple stressors. Consumers, in turn, consist of individuals and households with heterogeneous demographic characteristics. Poverty, for example, is closely related to the vulnerability in consumption. Although some discrete activities or actors are more vulnerable in the food system, vulnerability indicators should still focus on the overall food system and the critical linkages-for example, between agriculture and food retail or between consumption and food retail.

(5) What spatial and temporal boundaries should be used in measuring food system vulnerability? In the context of the Finnish food system, national-level measurement covers approximately $75 \%$ of the food consumed by the Finns. Measuring vulnerability at the national level also improves the analytical and statistical soundness, as well as data availability. However, in some cases, it may be appropriate to measure vulnerability at regional (e.g., foodshed), supply chain (e.g., global supply chains), organizational (e.g., in centralized industries), or even the certain demographic group (e.g., people using food aid) levels. The spatial boundary of vulnerability indicators depends on the vulnerability drivers. Vulnerability to climate change requires a longer timeframe, whereas vulnerability to economic and social drivers may have to be measured using a shorter timeframe.

There is a lack of literature dealing with food security in European countries. The starting point for studying food security in developed countries should be the vulnerability assessment of the entire national food system. Vulnerability assessments in the European context are heavily biased towards vulnerability to climate change. However, food systems are vulnerable also to economic, social, and institutional changes, which should be equally addressed. In addition, vulnerability and food security assessments tend to focus on agriculture (Wood et al. 2010), which neglects the critical linkages between production, processing, packaging, distributing, retail, and consumption.

Our study contributes to discussion on the assessment of national food security and food system vulnerability in developed countries. However, there are limitations in our study that deserve discussion. First, analysing the engagement in food security based on public documents may be biased due to the diverse terminology used by different organizations. Primary data based on personal interviews among key stakeholders should be collected in order to receive perceptions and attitudes to food security. Second, analysing food system vulnerabilities requires more 
comprehensive and detailed analysis. Our future aim is to build a vulnerability matrix of the food system, addressing the following questions: Food systems are vulnerable to what, and what food system activities are vulnerable? Third, defining more precise goals of vulnerability assessment (indicators) requires a participative stakeholder process, in which the feedback from the actors of the food system and the key stakeholders can be used in goal definition. Fourth, identifying the target group(s) and the associated purpose(s) for which the vulnerability indicators could be used is difficult because of the dispersed administration and management of food system-related matters. Fifth, defining spatial and temporal boundaries for vulnerability indicators depends largely on available data accuracy and accessibility. Hence, an exploration on the actual existing data and potential data need to be made in the future.

\section{Acknowledgement}

We would like to thank the Kone Foundation for financing our research project: "Future Food Security in Finland Identifying and Analysing Vulnerability Aspects in the Finnish Food System.” Additionally, we would like to thank the Foundation for Economic Education (Finland), which enabled our attendance at the Fourth International Conference on Food Studies in Prato, Italy. We would also like to thank the two anonymous reviewers for their suggestions and comments. 


\section{REFERENCES}

Adger, Neil W., and Kelly, Mick P. 1999. "Social vulnerability to climate change and the architecture of entitlements." Mitigation and adaptation strategies for global change 4: 253-266.

Barsley, William, De Young, Cassandra, and Brugère, Cécile. 2013. "Vulnerability assessment methodologies: An annotated bibliography for climate change and the fisheries and aquaculture sector." FAO. http://www.fao.org/3/a-i3315e.pdf. Accessed November 24, 2014.

Benson, Todd, Minor, Nicholas, Pender, John, Robles, Miguel, and von Braun, Joachim. 2008. "Global food crises: Monitoring and assessing impact to inform policy responses.” International Food Policy Research Institute, Washington, D.C. http://www.ifpri.org/sites/default/files/publications/pr19_1.pdf. Accessed November 24, 2014.

Birkmann, Jörn. 2013. "Measuring vulnerability to promote disaster-resilient societies and to enhance adaptation: Discussion of conceptual frameworks and definitions.” In: Jörn Birkmann (ed.) Measuring vulnerability to natural hazards. Tokyo: United Nations University Press, pp. 9-79.

Birkmann, Jörn. 2013. "Data, indicators and criteria for measuring vulnerability: Theoretical bases and requirements." In: Jörn Birkmann (ed.) Measuring vulnerability to natural hazards. Tokyo: United Nations University Press, pp. 9-79.

Brunori, Gianluca, and Guarino, Angela. 2010. "Security to whom? Changing discourses on food in Europe in times of a global food crisis.” In: Lawrence, Geoffrey, Lyons, Kristen, and Wallington, Tabatha (eds.) Food Security, Nutrition and Sustainability. Oxon: Earthscan, pp. 41-60.

Eakin, Hallie. 2010. “What is vulnerable?” In: Ingram, John, Ericksen, Polly, and Liverman, Diana (eds.) Food security and global environmental change. Oxon: Earthscan, pp. 78-86.

Ericksen, Polly, Bohle, Hans-Georg, and Stewart, Beth. 2010. "Vulnerability and resilience of food systems." In: Ingram, John, Ericksen, Polly, and Liverman, Diana (eds.) Food security and global environmental change. Oxon: Earthscan, pp. 67-77.

ESRC. 2014. "Master challenge: The UK food system." http://www.esrc.ac.uk/news-and-events/pressreleases/31583/master-challenge-the-uk-food-system.aspx. Accessed November 24, 2014.

FDA. 2012. "Vulnerability assessments of food systems: Final summary report." The U.S. Food and Drug Administration. http://www.fda.gov/downloads/Food/FoodDefense/ UCM317547.pdf. Accessed November 24, 2014.

Evangelical Lutheran Church of Finland. 2013. "Seurakunnat jakoivat ruoka-apua vähävaraisille yli 3 miljoonalla eurolla."

http://evl.fi/EVLUutiset.nsf/Documents/7DE56BBFF2C41F37C2257B25004EC333?OpenDocument\&lang=FI . Accessed March 3, 2015.

Holling, Crawford S. 2003. "The back-loop to sustainability.” In: Berker, Fikret, Colding Johan, and Folke, Carl (eds.) Navigating Social-Ecological Systems: Resilience for Complexity and Change. Cambridge: Cambridge University Press, pp. xv-xxi.

Hsieh, Hsiu-Fang, and Shannon, Sarah E. 2005. "Three approaches to qualitative content analysis.” Qualitative Health Research 15(9): 1277-1288.

Knuuttila, Marja, and Vatanen, Eero. 2013. "Domestic food production depends on imports.” In: Niemi, Jyrki, and Ahlstedt, Jaana (eds.) Finnish agriculture and rural industries 2013. Agrifood Research Finland Publications 114a. https://portal.mtt.fi/portal/page/portal/mtt_en/mtt/publications/fari. Accessed March 3, 2015.

Lang, Tim, and Barling, David. 2012. "Food security and food sustainability: Reformulating the debate." The Geographical Journal 178(4): 313-326.

Lee, Yung-Jaan. 2014. "Social vulnerability indicators as a sustainable planning tool." Environmental Impact Assessment Review 44: 31-42.

Peck, Helen. 2005. "Drivers of supply chain vulnerability: An integrated framework.” International journal of physical distribution and logistics management 35(4): 210-232.

Peters, Christian J., Bills, Neldon L., Wilkins, Jennifer L., Fick, and Gary W.2008 "Foodshed analysis and its relevance to sustainability." Renewable Agriculture and Food Systems 24(1): 1-7.

Ponis, Stavros T., and Koronis, Epaminondas. 2012. "Supply chain resilience: Definition of concept and its formative elements." The Journal of Applied Business Research 28(5): 921-929.

Reichertz, Jo. 2010. “Abduction: The logic of discovery of grounded theory.” Forum: Qualitative social research 11(1), Art. 13. http://www.qualitative-research.net/index.php/fqs/article/view/1412/290. Accessed December 1, 2014.

Schröter, Dagmar, Polsky, Colin, and Patt, Anthony G. 2005. "Assessing vulnerabilities to the effects of global change: An eight step approach.” Mitigation and Adaptation Strategies for Global Change 10: 573-596.

Smith, Lisa C., and Subandoro, Ali. 2007. "Measuring food security using household expenditure surveys." International Food Policy Research Institute, Washington, D.C. http://www.ifpri.org/sites/default/files/publications/sp3.pdf. Accessed November 24, 2014. 
Statistics Finland. 2013. “Ruuan hinta syö ostovoimaa.” http://www.stat.fi/ajk/tiedotteet/2013/uutinen_010_2013-0405.html. Accessed March 3, 2015.

UNEP. 2009. “The environmental food crisis.” http://www.grida.no/files/ publications/FoodCrisis_lores.pdf. Accessed November 24, 2014.

Transmango. 2014. Home page. http://www.transmango.eu/index.html. Accessed November 24, 2014.

Villa, Ferdinando, and McLeod, Helena. 2002. "Environmental vulnerability indicators for environmental planning and decision-making: guidelines and applications.” Environmental Management 29(3): 335-348.

Wood, Stanley, Ericksen, Polly, Stewart, Beth, Thornton, Philip, and Anderson, Molly. 2010. "Lessons learned from international assessments.” In: Ingram, John, Ericksen, Polly, and Liverman, Diana (eds.) Food security and global environmental change. Oxon: Earthscan, pp. 46-62.

\section{ABOUT THE AUTHORS}

Dr.Ari Paloviita: Researcher, Department of Social Sciences and Philosophy, University of Jyväskylä, Finland

Dr.Antti Puupponen: Researcher, Department of Social Sciences and Philosophy, University of Jyväskylä, Finland

Teea Kortetmäki: Researcher, Department of Social Sciences and Philosophy, University of Jyväskylä, Finland

Dr.Tiina Silvasti: Professor, Department of Social Sciences and Philosophy, University of Jyväskylä, Finland 